French, and Spanish pillaging of native American resources in the sixteenth and seventeenth centuries, during the heyday of piracy.

Sovereign governments may have legalized such plundering, but they were not necessarily more moral than the pirates who re-plundered that same wealth. Both used the threat of force, as Leeson reminds us. He does not argue for moral equivalency, rather he explains that pirates form their own versions of civil soci- eties for the same reason everyone else does: economic success.

The Invisible Hook is a good addition to the genre of popular economics: a fun and enlightening read, and rock solid in its scholarly bona fides.

Michael Shermer is publisher of Skeptic magazine, a columnist for Scientific American, and author of The Mind of the Market.

e-mail: shermer@skeptic.com

\title{
Solo journey to a fifth dimension
}

\section{Hypermusic Prologue: A Projective Opera in Seven Planes \\ Hèctor Parra and Lisa Randall \\ Pompidou Centre, Paris. 14-15 June 2009}

An opera about string theory and fivedimensional space is hard to imagine. But one premiered recently in Paris.

Hypermusic Prologue is a collaboration between composer Hèctor Parra and Lisa Randall, professor of theoretical physics at Harvard University and author of Warped Passages: Unravelling the Universe's Hidden Dimensions (Allen Lane, 2005), an account of cutting-edge physics, including string theory, and the possibility of additional spatial dimensions beyond those we sense. Singers James Bobby and Charlotte Ellett sang Randall's libretto, accompanied by musicians and technicians of the Paris-based Ensemble Intercontemporain. All gave admirable performances, with flashes of startling beauty.

Parra says that when he first read Warped Passages, something clicked. "For me it was a real discovery," he said. "For a few months I imagined reality vibrating like strings." The composer, who studied engineering before choosing music and whose father is a physicist, imagined a chamber opera in which music represented the phenomena of high-energy physics. He contacted Randall, who was keen to try a new genre. "In a book, if someone gets to some idea that they don't understand, they will stop", she explains. "You have more licence in a dramatic performance."

Parra's music is experimental, filled with glittering, jarring, liquid, fractured-icicle sounds, often electronically generated. It is as far from classical harmony as string theory is from clas- sical mechanics. "It was the right kind of music for this kind of physics precisely because it is esoteric," says Randall.

The plot of Hypermusic is simple: a pair of lovers, played by Ellett and Bobby, separate because the woman feels something is missing, both in her life and in physics theory. Both characters are physicists; the female protagonist is also a composer. In the middle of the hour-long show, she takes a trip into the fifth dimension, which she experiences with vivid delight. "It is a nice metaphor for exploring a new world," says Randall. "Of course, it's unrealistic." Also unrealistic is that the male character seems to be intellectually stuck in pre-Einstein physics. Randall added that "just for humour value".
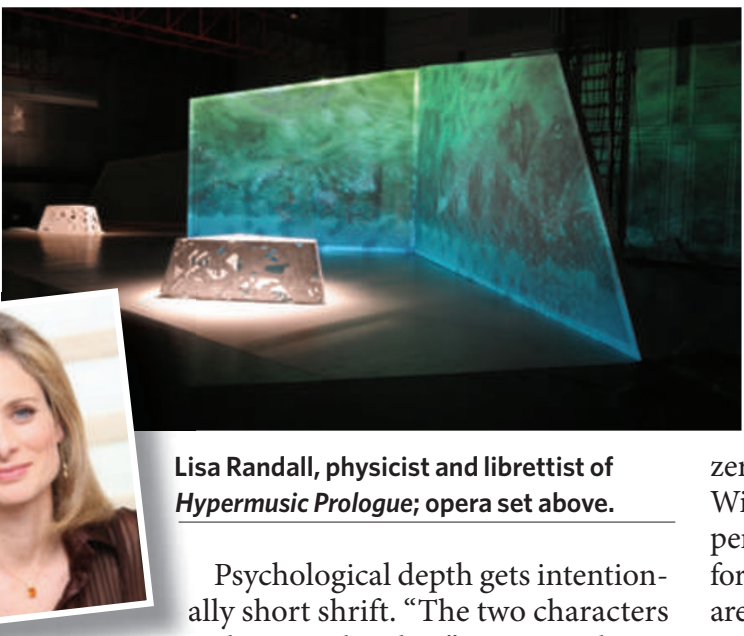

Lisa Randall, physicist and librettist of Hypermusic Prologue; opera set above.

Psychological depth gets intentionally short shrift. "The two characters are schemes, sketches,” Parra explains. And the quantity of technical language in the libretto is breathtaking. "There's more physics in it than I had intended," says Randall. The composer and the production designer convinced her to include more, for atmosphere. "When you watch a movie about a painter you don't learn how to paint," she explains. "But you learn what it was for the painter to get immersed into that world."

Randall describes in Warped Passages how our familiar world is confined to a four-dimensional space-time 'brane' that lies, in her theory, within a larger five-dimensional 'hyperspace'. Moving into the fifth dimension takes the fictional traveller into regions of vastly magnified gravity that distorts other attributes of reality and experience: time, distance, energy and mass.

The challenge was to depict this exotic journey as a beautiful experience for the audience. Parra samples the sounds produced by the singers and instruments and passes them through an elaborate digital system of real-time signal processing and synthesis. The instrumental and vocal scores are of stunning complexity, with more than 100 parameters of digital transformation, which evolve as the plot progresses. The warping of physical time, as experienced by Ellett's character, for example, is expressed through modulations of rhythm and the 'granularity' of the synthesized music.

The processed sounds are projected into the auditorium from an array of speakers, using signal delays that constantly shift the apparent locations of their sources. The audience hears this complex aural texture blended with the sounds produced directly by singers and instrumentalists. "You hear 70\% the real musicians and 30\% electronics, on average," Parra says.

The set is an articulated screen on which artist Matthew Ritchie projects video images evoking the two characters' conflicting perspectives. The kaleidoscopic, lava-lamp style of the images evokes a psychedelic atmosphere that seems slightly out of register with the idea that the fifth dimension is physically real.

By contrast, Lisa Randall is a scientist who stays close to experimental data. "I'm not a string theorist, I'm a model-builder," she says. "One of my fears was that by the time this happened we'd find out it wasn't even right." Experiments testing her ideas are expected to run in the Large Hadron Collider at CERN, Europe's particlephysics laboratory near Geneva, Switzerland, after it starts up again later this year. With luck, they might coincide with upcoming performances of Hypermusic. "It's a good time for science to inform art," says Randall. "People are interested. If there were extra dimensions, people would want to know."

Stefan Michalowski is a former particle physicist, currently working on intergovernmental science policy; Georgia Smith writes for the International Herald Tribune's 'Ear for Opera' series.

e-mails: stefanm@noos.fr; georgias@noos.fr

Hypermusic Prologue will be performed on 27-28 November at Gran Teatre del Liceu, Barcelona, Spain, and on 6 December in the Grand Auditorium of the Philharmonie, Luxembourg. 